\title{
NOTAS SOBRE LA INVENTIVA EN LA LITERATURA LATINOAMERICANA RECIENTE
}

\author{
Notes on inventiveness in recent Latin American Literature
}

\section{RESUMEN}

A partir de la lectura de Un año sin primavera de Marcelo Cohen, este ensayo reflexiona sobre la preocupación ecológica en las narrativas contemporáneas, el discurso de autoficción y las limitaciones propias del lenguaje en su aprehensión de lo real. En contraste con una corriente monocorde de autoficción que destacaría en la literatura reciente, el registro y la propuesta de Cohen, fundado en la inventiva lingüística e imaginaria, constituye una apuesta cuyas orientaciones formales e imaginativas pueden extrapolarse a otras narrativas recientes: Schweblin, Meruane, Geisse y otros. En resumen, se reconoce una corriente de experimentación formal y de esfuerzo imaginativo en la literatura latinoamericana reciente. Son propuestas narrativas disímiles que, sin embargo, confluyen en exploraciones estéticas y éticas, a la vez que esbozan vidas imaginables en un intento por potenciar desde la imaginación miradas alternativas ante proyectos geopolíticos y vitales que se autodesignan como las opciones ineludibles de nuestro presente.

Palabras claves: Marcelo Cohen, narrativa latinoamericana reciente, imaginación, ecoliteratura.

\section{UNIVERSUM}

\author{
Revista de Humanidades y Ciencias Sociales
}

\section{BETINA KEIZMAN}

Dra. en Letras. Universidad Alberto Hurtado. Santiago, Chile. Correo electrónico: betkeiz@yahoo.com.

Este ensayo forma parte del Proyecto regular FONDECYT No n 1170129 (2017-2020). Universidad Alberto Hurtado: "Perspectivas ampliadas: formas de vida, comunidad y poética en las narrativas contemporáneas en Chile, México y Argentina”.

Artículo recibido el 12 de marzo de 2019.

Aceptado el 19 de julio de 2019. 


\section{ABSTRACT}

From the reading of Marcelo Cohen's Un año sin primavera, this essay thinks over the concern about ecology in contemporaneous literature, autofiction discourse and own limitations of the language in its evaluation of reality. Mirroring Cohen's range and proposal with that stream of autofiction monotone literature that apparently stands out of the recent (up to date) literature, the linguistic and fantastic imagination appears as a key element that can be extrapolates to other recent narratives: Schweblin, Meruane, Geisse and others. To sum up, we can observe a current of strict experimentation as well as of imagination emphasize in recent Latin American Literature. Those are different narratives proposals that, however, join themselves in aesthetics and ethics explorations, as well as drafts futures or lives able to be imagined in a try to power, from the imagination, alternative regards in front of geopolitical and vital projects that self-design as unavoidable options of our present.

Keywords: Marcelo Cohen, recent Latin American narrative, imagination, ecoliterature.

En Un año sin primavera, Marcelo Cohen transpone ensayo y autoficción para rastrear sensiblemente el cambio climático en su experiencia personal y cotidiana, a la vez que atiende a las modulaciones en que el arte poético, esa captación de lo sensible, ha articulado a lo largo del tiempo su relación con la naturaleza. Para reforzar este recorrido, su escritura circula por tres zonas: la propia experiencia (y aquí elige el registro de la autoficción), un recuento crítico de los rastros de la naturaleza y de las especies animales en la poesía contemporánea (es el turno del formato ensayístico) y la exploración de fuentes en internet (y aquí cuentan los recursos de archivo y de imaginación de los que se vale el escritor contemporáneo). De la mano de esta combinación, Cohen introduce en su escena de escritura la mayor preocupación del presente, esto es la que se incrementa en relación con el planeta y el futuro de la humanidad. Para esta inquietud propone un tratamiento híbrido que avanza por el bies de sus propios intereses y de recursos comunes de la rutina 
contemporánea: escenas de caminata, lectura y búsquedas en internet. No es nueva la vigilancia de Cohen, modulada como escucha y atención, en torno al cambio climático. Bajo la influencia de lo que hoy se denomina "preocupación antropocénica", su obra narrativa, o poética-narrativa, desarrolla desde hace años gran parte de su imaginación distópica en una geografía inventada, el delta panorámico, una región que le permitió ensayar desde la ficción toda suerte de experiencias subjetivas, colectivas y políticas al filo del tiempo. En Gongue, por ejemplo, Cohen conjetura un ámbito rural bajo las aguas donde contados sobrevivientes custodian los restos materiales de una finca para sustraerlos de posibles saqueadores.

A lo largo de más de 20 libros, Marcelo Cohen se confirma un escritor cuya exploración escapa de automatizaciones del lenguaje y de la imaginación. La suya es una ficción obstinada por torcer las vías previsibles. Por eso mismo, aunque también su producción en el ámbito del ensayo es importante, la aparición de un libro como Un año sin primavera llama la atención por su factura en cuanto al género, y me estoy refiriendo a su deslizamiento hacia la autoficción explícita bajo la forma de un diario. Numerosos ensayos anteriores nos acercan a Cohen-lector, pero tal vez sea la primera vez en que su escritura profundiza a tal punto la materia y los quehaceres de un escritor. Para evaluar esta "novedad", se hace necesario subrayar que es difícil imaginar a Cohen sucumbiendo a una moda. Habría que marcar aquí una línea generacional para recordar que su escritura ha proyectado a lo largo de los años una política, una suerte de norte que orienta el conjunto de su trabajo, tanto en sus textos como en sus intervenciones públicas, manteniéndolo en un incontestable perímetro de fidelidades estilísticas y temáticas. Lejos de una concesión a la moda, es factible, por qué no, suponer un Cohen sensible a lo que las formas literarias y sus convulsivas olas, en este caso "el registro del yo", puedan aportarle. Tamara Kamentzain, en Una intimidad inofensiva. Los que escriben con lo que hay, su inspirador libro de ensayos sobre los formatos de la intimidad en autores recientes, postula la intensificación de lo que denomina una intimidad inofensiva cuyos rasgos y corolarios pueden servir aquí de contrapunto para no tomar a la ligera algunas particularidades de esta operación escritural de 
Marcelo Cohen. Según Kametzain, esta intimidad inofensiva, lo que otros han considerado bajo la denominación de "giro autobiográfico", combina cotidianidad e intimidad, pero sobre todo consolida un tono monocorde, incipientemente menor, emanado de un modelo de escritor venido a menos, vale decir, de un individuo cuyo rol y crédito social ha sufrido una consistente degradación. Es un hecho en relación a muchos de los autores a los que se refiere Kametzain, pero dudaría en aplicar esa consideración a Marcelo Cohen, tampoco la extendería a otro escritor del que también Kametzain se ocupa, Sergio Chejfec. Es cierto que la exposición de sus entretelones como lector y escritor buceando en internet, sus estrategias creativas nutridas aquí y allá por una noticia de periódico leído en línea, contribuyen sin duda a desentronizar el personaje del autor ajeno a lo cotidiano, sin embargo conserva su distancia respecto de esa realidad sin espesor que Kametzain reconoce en los poetas Fernanda Laguna o Cucurto y en narradores como Alejandro Zambra o, de nuevo, tal vez con premura, en Félix Bruzzone.

En Cohen la cotidianeidad está en resistencia, a veces en abierta rebeldía ante la tentación monótona. Lo monótono, recordemos, carece de entonaciones y matices. Para Cohen la imposibilidad de darle espesor y consistencia imaginativa a nuestra existencia en el mundo constituye condición por excelencia para la rebelión de su escritura. Se escribe contra esa imposibilidad, a sabiendas de ser derrotado de antemano. Coincide así con lo Juan José Saer denominó la selva espesa de lo real, en el ensayo que bajo ese nombre incluyó en El concepto de ficción, otra forma de nombrar la materia misma contra la que se yergue (y se apoya) la escritura. Por su parte, cuando Clément Rosset se suma a esta polémica antigua, indica que la dificultad de acceso a lo real es innata al vínculo lingüístico, en suma, al orden de existencia entre seres humanos y mundo. Así lo pronuncia Francis Ponge en "Poemas habitantes": "Por rencor contra su inmensidad que lo abruma, el hombre se precipita a las orillas o a la intersección de las cosas grandes para definirlas". Según Rosset, la pared perceptiva y emocional que encapsula al humano solamente se quiebra bajo condiciones extremas: drogas, locura, 
terror, pesadilla y erotismo.

Ese fue el balance de la modernidad, en la actualidad global, nuevos actores contribuyen a hacer más crítica esa imposibilidad de acceso a lo real: son la espectacularización de la existencia, acentuada por los procesos modernizadores ligados al capitalismo, de la mano de medios masivos que monopolizan el intercambio entre receptor y mundo. Resumo, si desde el principio de los tiempos no hay acceso a lo real porque así lo dicta la condición inicial de la relación entre ser humano y mundo; esa imposibilidad se ve elevada a nuevas potencias por la espectacularización que mediatiza nuestra relación con los otros y con nuestro entorno. En este punto, rescato otros dos factores que resultan sustanciales arrastrar hasta esta discusión: en primer lugar, el rol del gran archivo del mundo, los dispositivos de recopilación, memoria y circulación informativa que conocemos bajo el nombre de internet; segundo, la creciente complejidad de los órdenes contemporáneos, si atendemos la dificultad de aprehender las intrincadas redes del mundo contemporáneo, aquello que Bruno Latour (2012) denomina cuasi objetos o cuasi sujetos para referirse justamente a fenómenos complejos (el caso ejemplar del cambio climático) en los que interactúan disposiciones discursivas, sociales, culturales, biológicas o naturales imposibles de desanudar, o siquiera concebir como experiencias unitarias, por lo tanto o autónomas, incluso en un plano de análisis. Toda la obra de Cohen se desarrolla en torno a estas disposiciones de cuasi objetos y cuasi sujetos, con una escritura que batalla su intento titánico por aprehender y transmitir la complejidad.

Cohen, entonces, aparece en este libro como un personaje que lee y colecciona información relativa al cambio climático. Resulta una novedad en un autor tan ligado al mundo literario como lo es Cohen una escena de escritura donde las redes virtuales devienen motor creativo. Buen cultor de la ciencia ficción, las tecnologías nunca han sido ajenas a su pulso imaginativo, a una narrativa que entrama creaciones como la panconciencia, o los ciborgues, distintas variaciones de las redes y sus tecnologías contemporáneas. Pero ya no se trata de ficcionalizar, bien pasado por el tamiz distópico, las consecuencias políticas y psíquicas de estos dispositivos en las comunidades y los sujetos 
contemporáneos, ni siquiera de modular posibles alter ego del artista; Un año sin primavera pone en relieve la intervención efectiva de estos dispositivos virtuales en las prácticas creativas actuales. Es este reconocimiento fundamental el que empujó a Cohen al registro de la autoficción. Ante la pregunta de cómo produce, crea o imagina un escritor contemporáneo, no solamente aparece, como es evidente, el teclado y la computadora, o algún otro dispositivo o herramienta de la realización material de la escritura. El internet, la búsqueda, el encuentro fortuito y el puente entre links son manifestaciones vigentes de un archivo ampliado y de canales de confluencia que establecen el nudo inicial de numerosas ficciones, cuando no aportan de modo directo a su potencia constructiva e imaginativa.

Gongue de Marcelo Cohen es una novela morosamente "ecologista" que converge con el maravilloso cuento "La casa inundada" de Felisberto Hernández a la hora de urdir mundos acuáticos. Las dos narraciones crean universos de agua, aunque Felisberto sondea explícitamente un mundo de artista, aquel que podía concebir un escritor nacido en 1902. En el cuento de Felisberto, Margarita, una mujer enorme, ermitaña y silenciosa edifica una casa inundada, rodeada por canales donde los personajes se movilizan en un bote, acercándose a camas, armarios y objetos que flotan sobre gomas infladas. Los detalles son magníficos: en la vereda que rodea al lago, para ejemplo, hay sapos de bronce esparcidos para atar el bote.

Los habitantes de la casa moran por esa superficie movediza, un piso acuático que dificulta los menores desplazamientos al tiempo que provoca la extrema percepción de los propios movimientos y del entorno. El ojo de agua es un amplificador irredento de lo que sucede, cuando no la encarnación o la materia de la imaginación y la sensibilidad:

Ella no quiere que tiren papeles ni ensucien el piso de agua. Del comedor al dormitorio de la señora Margarita no hay puerta y una mañana en que se despertó temprano, vio venir nadando desde el comedor un pan que se le había caído a mi mujer. A la dueña le dio mucha rabia y le dijo que se fuera inmediatamente y que no había cosa más fea en la vida que ver nadar un pan (70).

Cada tanto, la señora Margarita ordena poner en movimiento las 
válvulas y regaderas y organiza una ceremonia haciendo naufragar budineras, pequeñas barcas adornadas con velas encendidas. Se trata de rituales de conexión. Así lo explica el narrador: "yo me moriré con la idea de que el agua lleva adentro de sí algo que ha recogido en otro lado y no sé de qué manera me entregará pensamientos que no son los míos y que son para mí" (88-89). La novela Gongue, y de un modo más amplio la escritura de Cohen, invoca unos espacios de la imaginación similares, incluso si, más de medio siglo más tarde, aparecen irremediablemente socavados por el desastre.

Vuelvo a Un año sin primavera de Cohen. El libro inicia con la llegada de un correo electrónico, continúa con una reflexión sobre los usos espurios del lenguaje y encalla en el fastidio del narrador por el abuso de ciertos términos, "raro", "como raro", e inefable. La retórica de la pereza del lenguaje crítico que el escritor denuncia se inspecciona justamente en el término "inefable" que brilla, justamente, por su imprecisión. Para definir lo inefable Cohen cita a Curtius, quien se refiere al "hábito de 'insistir en la incapacidad de hablar dignamente del tema"' (8). Hábito, insistir y hablar dignamente se ligan con la incapacidad, frente a "la conciencia de la enormidad de relaciones que los lenguajes prácticos expulsan" (9). Se trata, subraya Cohen, de una deficiencia de capacidad expresiva. Luego se refiere a la explicación de Blumenberg para quien lo inefable es un aspecto de un fenómeno más amplio, lo inalcanzable, que varía a lo largo de la historia. El encanto de la meteorología, apunta Cohen, nunca decae porque los fenómenos atmosféricos continúan siendo imprevisibles, y por lo tanto, sigo yo, inalcanzables, incluso inefables.

Llegado este punto, aquello que Tamara Kametzain reconoce en las escrituras del yo como modulaciones íntimas, o casuales, o disruptivas, bajo la pluma de Cohen no constituyen de ninguna manera un registro lingüísticamente irrelevante. Cito un ejemplo:

La atmósfera tiene su estilo; es dionisíaca. Los cambios atmosféricos son escándalos en la pauta del tiempo crónico. Mas ahora, cuando, con la conciencia tomada por dispositivos y prótesis indefectible, con la urgencia tomada de hacerse productor y gestor eficiente sí mismo, de ganarle al reloj y al calendario para crecer, consumarse como y en proyecto, por el mandato de disfrutar y mimarse como está prescrito sin que decaigan los rendimientos, y encadenada rendir y recibir información verbal y fotográfica inmediata sobre cada pormenor íntimo y noticia política, el tiempo de la 
vida sólo aprueba fugaces vistazos sobre la enormidad exterior a la pyme personal (11).

En resumen, la intrusión de Cohen en el registro del diario es una usurpación, es una apropiación de registro, el ensayo de un formato que le permite redoblar su apuesta literaria. Lejos de sucumbir a un tono menor, su escritura pulsa una exaltación de la materia y de la experiencia, un acercamiento que roza la epifanía, en síntesis, una ambición suficiente ante la imposibilidad de aprehender el mundo por la palabra.

Cohennace en 1940, no es un escritor reciente, término que habitualmente reservamos para voces más jóvenes. Sin embargo, su trabajo ilumina con una profundidad extraordinaria apuestas fundamentales de la literatura reciente. Por una parte, Cohen adscribe plenamente a un espíritu narrativo que enaltece lo ficcional, donde la inventiva tiene un lugar predominante, ese tipo de gesto creativo que en mayor o menor medida el discurso crítico contemporáneo ha invisibilizado. Sin embargo no son pocas, al contrario, son muchas las propuestas que podríamos, con timidez, designar como de inventiva, una denominación aplicada en modo provisorio a aquellas escrituras en que el ensayo formal y la conciencia performativa y productiva de la escritura ocupa un lugar primordial, aliado a esfuerzos imaginativos evidentes (nombro aquí a Mario Bellatin, pero también a Lina Meruane, a Cristina Rivera Garza, a Verónica Gerber, a Bruno Lloret, a Roque Larraquy, María Sonia Cristoff y tantos otros). A veces, o siempre, la trampa generacional nos engaña con su tábula rasa. Es falso que la mayor parte de las producciones recientes se asimilen a tratamientos de tintes más o menos realistas, autoreferenciales, de registro mesurado, como diría Kametzain. Reintroducir las nociones de imaginación, creación, densidad e, incluso, epifanía, resulta fundamental para abordar otro conjunto de obras, en algunos casos las mismas obras, pero con otras lecturas que entienden lo inefable como "una declaración de impotencia frente a lo importante, lo esencial" (12).

Grata paradoja, con el paso de los años la narrativa de Cohen se vuelve más y más anticipatoria. Sus preocupaciones personales, estéticas y vitales se asoman hoy al centro de la escena, es decir que se produce la "novedad" 
de que un escritor de márgenes comparta un espacio monopolizado por escritores que desde sus inicios fueron más difundidos y masivos (pongamos Samanta Schweblin o Lina Meruane, para mencionar dos nombres). Se trata de una verdad a medias, porque enfrentado a la dificultad de abarcar un todo, o siquiera horadar las capas sedimentadas de las muy diversas experiencias sociales, políticas y económicas de la contemporaneidad, Cohen derivó una escritura espesa, bifurcada, plenamente rizomática que lo vuelve a lanzar hacia los bordes del lenguaje y, por consecuencia, de nuevo a las fronteras del circuito literario.

Los escritores se hunden, o pueden hundirse, cuando no conquistan mecanismos formales e imaginativos para vincularse con los problemas de su tiempo, y lo que he llamado inventiva narrativa es, en Cohen y en otros escritores, la respuesta a este desafío. Propongo, después de esta larga introducción, explorar algunos de estos mecanismos en ciertas novelas contemporáneas. Distancia de rescate de Samanta Schweblin narra en clave de relato de fantasmas, la muerte y la enfermedad de niños y adultos debido a la exposición a los agroquímicos en un sector rural sojero. El único y radical escape de esa condena a muerte reside en la intervención de la curandera del pueblo, quien libera los cuerpos enfermos (por lo menos en el caso de los niños) y hospeda sus "espíritus" en otros cuerpos, en uno o en varios, en una política de migración de almas que surge como desesperada solución frente la acción invisible del glifosato. En escasas 125 páginas, Schweblin trenza un complejo argumento que escapa a la alegoría y que se amplifica drásticamente en una dinámica que recuerda la intersección de redes. Se trata de una secuencia narrativa que ramifica el impacto de los agroquímicos y la búsqueda febril de beneficios asociado a las nuevas tecnologías transgénicas y lo liga a políticas de familia, el rol paterno y materno, a la viabilidad de modelos económicos y sociales y al agenciamiento, o falta de agenciamiento, de las comunidades. La dificultad para discernir e identificar los problemas que aquejan a los protagonistas y a la comunidad de la novela desemboca, por fin, en la fluidez de los cuerpos para disolverse y transmigrar gracias a una implícita disponibilidad del sujeto como secuencia informativa y vida 
afectiva. ¿Qué es lo que transmigra? ¿El recuerdo, el pasado, los afectos, la personalidad, las experiencias?: no lo sabemos. Estos presupuestos narrativos incluyen algún grado de salvación, pero también mucho de angustiosa pérdida, por eso la novela se expande hacia un cuestionamiento sobre la maternidad, las relaciones intrageneracionales y las responsabilidades éticas en que estas relaciones se asientan. ¿De qué modo esta novela expone o transmite la complejidad de los fenómenos contemporáneos, pero sobre todo, qué supone esta complejidad en una obra literaria? Quiero decir, ¿cuáles son los desafíos escriturales e imaginativos que solventan su eficacia narrativa?

El primer acierto es que Schweblin haya elegido para su novela una estructura de diálogo. Toda la novela es un diálogo, como mínimo, un diálogo entre dos personajes, entre Carla, una madre también intoxicada y al borde de la muerte, y el espíritu fantasmal de David, otro niño enfermo que ha sido "transmigrado". En un orden casi socrático, ese diálogo, tan extenso como el libro mismo, orienta a la moribunda hacia el autodescubrimiento de los sucesos que protagonizó, también de aquellos que no alcanzará a ver en carne y hueso, posteriores o inmediatos a su muerte, pero que vigila desde una mirada panóptica, escindida de su cuerpo yacente. El "nosotros" de la novela es el nosotros de los enfermos, incluso el de David en el hospital habitando su propio cuerpo y fraccionado en los cuerpos de otros.

El diálogo supone oralidad, desacelera, el diálogo divaga, se confunde, alcanza el juicio gracias a la contribución de interlocutores. Es una práctica antigua, la primera tecnología comunicativa que, en la novela, recupera sus dimensiones pedagógicas. La voz propedéutica de David guía esa conversación, que también remeda una sesión psicoanalítica en que la moribunda repasa actos propios y ajenos para adjudicarles un sentido. La pulsión pedagógica de David, sus indicaciones y sus preguntas fuerzan la mirada de su interlocutora moribunda a atender tal y cual punto, y a descartar otro, anticipando en la desmaterialización de esa perspectiva (recordemos que Carla está semiinconsciente en una cama de hospital), la desmaterialización de los cuerpos que el relato procesa como única solución a los organismos y a un sistema enfermo. El vínculo que debe entender la moribunda, ese juego 
de redes y esa complejidad que el argumento asume, es el mismo que debe comprender el lector en una progresiva admisión de lo subsumido bajo la apariencia bucólica del campo cultivado, en definitiva, los efectos devastadores de las agriculturas del postcapitalismo. Lo que se entiende es el precio a pagar por la búsqueda desmesurada de beneficios.

Cuando las víctimas no entienden, no ven, no comprenden, la novela subraya la enorme dificultad para aprehender el desastre, aprehender en el sentido de asimilar y apropiarse de un conocimiento, pero sobre todo aprehenderlo afectivamente. La insistente reflexión metatextual sobre cómo ver y qué ver, sobre cómo interpretar y entender, comunica un esfuerzo extremo de transmisión de las redes cognitivas, vinculares y afectivas que sustentan la trama. El resultado es una escenificación de las dificultades, en primer lugar la de forzar un juicio a contrapelo de los relatos oficiales, que se confronte con interpretaciones en clave de balanza de costos-beneficios, las llamadas zonas de sacrificio. En el libro En tiempos de catástrofes. Cómo resistir a la barbarie que viene, Isabelle Stengers discute las dificultades epistemológicas, estratégicas y prácticas para ejercer lo que ella denomina "prestar atención", es decir saber detectar los problemas y poder abordarlos en su justo valor. En el diálogo de la novela de Schweblin se alza una disposición análoga. No está en juego un acceso estrictamente cognitivo a un problema complejo. De algún modo, las problemáticas que desfilan en la novela constituyen un horizonte de saberes que nosotros, los lectores, compartimos por ser habitantes del presente. Quiero decir, el niño fantasma le explica a la moribunda, y a nosotros, aquello que ya sabemos, los desastres ecológicos ocasionados por las fumigaciones e intervenciones agroquímicas en los procesos de producción de alimentos. En segundo plano, la novela rastrea el pánico que genera la incapacidad de concebir acciones que amortigüen o cancelen el desastre anunciado. En ese sentido, la novela de Schweblin resigna la denuncia de los hechos y, a cambio, posibilita una ampliación en el plano afectivo y especulativo en relación a las consecuencias ya ocurridas, pero también las que se extrapolan a futuro de los desastres ecológicos.

La inventiva narrativa está al servicio de hallar mecanismos estéticos y 
éticamente eficaces para que la literatura lidie con los problemas de su tiempo. Para pensar estos mecanismos con mayor precisión me gustaría recuperar una denominación borgeana, la invención circunstancial. En el ensayo "La postulación de la realidad" Borges desarrolla la oposición entre lo estético y lo expresivo con un razonamiento seductor, bien que débilmente argumentado. Como no es de extrañar, rechaza la exposición de las emociones propias o ajenas, y elige, sin falta, las huestes de lo estético. Lo que él denomina la escritura clásica "no escribe los primeros contactos de la realidad, sino su elaboración final en concepto" (217). "La simplificación conceptual de estados complejos es muchas veces una operación instantánea. El hecho mismo de percibir, de atender, es de orden selectivo: toda atención, toda fijación de nuestra conciencia, comporta una deliberada omisión de lo no interesante" (218). La estética de la selección apela a la necesidad de fijar un hecho complejo, incluso inagotable, en la limitación de la palabra. La imagen ya fraguada, señala Borges, "constituye un bien público" (218). ¿Qué imagen constituye hoy un "bien público"? Ya en 1931, Borges intuye en estas líneas que la presión exuberante de los grandes medios de comunicación sobre el campo imaginativo empuja y empujará el arte hacia un terreno de sequedad imaginativa. Entre las tres formas de la postulación clásica de la realidad, Borges reconoce la invención circunstancial como el recurso "más difícil y eficiente de todos" (220). Propone el ejemplo de La gloria de Don Ramiro, una novela de tinte modernista escrita por Enrique Rodríguez Larreta, prácticamente olvidada ya por entonces. La invención circunstancial es la siguiente: "ese aparatoso caldo de torrezno, que se servía en una sopera con candado para defenderlo de la voracidad de los pajes" (220). La sopera con candado y la voracidad de los pajes insinúan bien "la miseria decente, la retahíla de criados en el caserón lleno de escaleras y vueltas y de distintas luces" (220). Luego agrega que la invención circunstancial no es un recurso estrictamente literario, es decir que su eficacia no residiría, contra lo que pudiera colegirse, en un funcionamiento de "pura sintaxis" o "destreza verbal" (220). En suma, Borges se refiere a cierta construcción estética e imaginativa que permite el desenvolvimiento de una larga proyección de sentidos, intuiciones y estados 
afectivos que se desprenden de esa invención circunstancial.

Resulta, aquí quería llegar, que muchas novelas recientes restituyen de un modo privilegiado ese tipo de inventiva. En la novela de Schweblin, Distancia de rescate, el título ya alude a esta invención en el concepto de "distancia de rescate", a saber, la distancia que la madre puede alejarse de su hija sin exponerla al peligro. Es una inventiva narrativa, un concepto con el que el personaje y la novela juegan para demostrar tanto el riesgo y la necesidad de protección como para esbozar la materialización del peligro invisible que acecha. El problema fundamental en la trama es que esa distancia se devela ineficaz cuando la amenaza escala a una dimensión sin fronteras, definida por los efectos del capitalismo y por la crisis antropocénica. En esos términos, el desenlace de la novela es elocuente:

Sólo entonces mi marido enciende el motor, baja la lomada y toma el camino de ripio. Siente que perdió demasiado tiempo. No se detiene en el pueblo. No mira hacia atrás. No ve los campos de soja, los riachuelos entretejiendo las tierras secas, los kilómetros de campo abierto sin ganado, las villas y las fábricas, llegando a la ciudad. No repara en que el viaje de vuelta se ha ido haciendo más y más lento. Que hay demasiados coches, coches y más coches cubriendo cada nervadura de asfalto. Y que el tránsito está estancado, paralizado desde hace horas, humeando efervescente. No ve lo importante: el hilo finalmente suelto, como una mecha encendida en algún lugar; la plaga inmóvil a punto de irritarse (124).

La mirada panóptica y descarnada duplica el abandono de la transmigración de espíritus, pero también supone una ampliación de perspectiva que se deslocaliza de la zona sojera donde se desarrolla la novela y se dilata hacia la ciudad, en primer lugar, luego, podemos inferir, hacia el planeta completo. La distancia de rescate es una categoría ineficaz en relación con los personajes (no permite la salvación de los niños), pero su eficacia narrativa se cifra en que expresa la complejidad del problema y la limitación de las herramientas afectivas y estratégicas, cognitivas y convencionales con que se lo enfrenta.

Este hilo suelto, esta mecha que arde, también remite a la otra inventiva narrativa con que la novela alude al riesgo de la dispersión: lo que se ata, lo que se pierde, lo que se retiene y lo que se desvanece. Cuando la curandera 
opera la transmigración de los cuerpos lo hace atando a los niños. Luego, el niño, ya trasmigrado, también ata los objetos que están en la casa, unos a otros, aterrorizado ante la posible disolución, un estallido o una descarga que depondría los objetos bajo los efectos de un aire sin atmósfera, flotando indefectiblemente, transportados por fluidos invisibles, neutralizada la fuerza centrífuga que los ata a la tierra. Es una imagen intensa que, como Borges requería, se amplifica en una retahíla de sentidos y sugerencias, una inventiva narrativa circunstancial, arbitraria, que también recuerda la superficie de fluidos de "La casa inundada" y de Gongue, donde los personajes utilizan enigmáticos gongs para transmitir sus mensajes.

Otro ejemplo de inventiva narrativa. Fruta podrida de Lina Meruane parte de la insurrección de una enferma que se resiste a tratar su diabetes $\mathrm{y}$, desde esta condición inicial, desarrolla un argumento de correspondencias entre el tráfico de órganos y la circulación de mano de obra en el mundo global, la experimentación científica sobre cuerpos precarios o periféricos y el tránsito de materias primas, saberes y capitales en nuestra actualidad globalizada. La novela sigue una lógica análoga a la de Schweblin en una amplificación que va de lo local a lo global, y también sufre de un peligro equivalente de diseminación, incluso en mayor grado que Distancia de rescate, un relato cuyos presupuestos narrativos permanecen más acotados, aun si sus implicancias se amplían, en el desenlace, a todo el planeta.

En las narraciones recientes a las que me estoy refiriendo, la vida individual de los sujetos pierde intensidad al tiempo que cede su rol de promotor de peripecias. Las narraciones se vuelcan, con singular ímpetu, hacia dinámicas entre sujetos y mundo, en relaciones de más en más inclusivas, complejas y recíprocas. Evidentemente, esta pulsión centrípeta de los relatos genera problemas estrictamente narrativos. Las ramificaciones e inferencias, tránsitos y vínculos, eso que he llamado complejidad de los fenómenos contemporáneos orilla los argumentos hacia una zona incomprensible, amplia, de interconexiones, que es propia de las redes del capitalismo global del presente. Mark Fisher reconoce en esta incomprensibilidad un vínculo entre capitalismo global y lo espeluznante, definido como aquello que orienta el 
sentido de hechos que no somos capaces de controlar ni conocer en todas sus dimensiones. Nos movemos en ese terreno de incomprensión. Propongo un ejemplo: ¿Quién podría explicar cabalmente los alcances de la utilización de WhatsApp en los sistemas electorales contemporáneos, incorporando al análisis dimensiones económicas, políticas, técnicas, afectivas y sociales? Justamente, para enfrentar esas incomprensiones radicales que poco o nada restringen las certezas sobre sus efectos, las novelas expanden sistemas de elisiones, tejen circulaciones y procesos. En el caso de Fruta podrida se potencia un régimen de analogías entre el tratamiento de las frutas y el control de plagas, el tratamiento de la enfermedad y la política de los trasplantes, la reproducción planificada, las rebeldías y el sabotaje en la producción agrícola y en el control de la enfermedad y de los cuerpos. Son estos deslizamientos y amplificaciones los que instauran una economía de interconexión que alimenta el fluir estilístico de la narración:

Zoila era un bicho recién fumigado. Era una mosca enredada en la alfombra de la araña, el puro armazón de un insecto recién vaciado. La miraba sin reconocerla, pero la reconocía mientras le entraba una bulla en la cabeza, o un zumbido en los tímpanos y arcadas de cuatro meses o cinco; y en ese momento vertiginoso empezó a torcérsele dentro un remolino de excusas, de escupos, de vómitos, y largas fórmulas químicas y un qué hago con esta al cubo, equivalente a una dosis de sulfuro, cavando hoyos alrededor, me oye, la depreciación de las divisas, de las manzanas o naranjos o dólares, dónde me largo y qué porcentaje del mercado, del accidente doméstico con potasio, con pesticidas orgánicos, una temporera de turno, eso, un temblor, un trasplante, un tumulto de médicos... (15-6)

Así, la yuxtaposición de campos semánticos, el deslizamiento metonímico y la multiplicación de sustituciones metafóricas constituyen el encofrado que otorga densidad al conjunto, pero sobre todo, lo dota de un sentido que se sostiene por el vínculo.

El problema evidente, que deriva de una necesidad de eficacia narrativa, es cómo anclar sentidos y/o permitir que el lector los construya en una ficción en constante fluctuación, en una situación de infinita interconexión, bajo una arquitectura densa por la ambigua complejidad. ¿Cómo se dispone lo móvil y lo complejo, lo que solo existe en la interrelación? Las instancias de detención 
en la narrativa de Fruta podrida deben entenderse desde esta perspectiva, pensarse desde esta función. Y aquí reaparece, bien que transformada, aquella invención circunstancial borgeana, la inventiva narrativa que permite encarnar estéticamente la complejidad e inyectarle una materialidad cognitiva y sensible. "Pies en la tierra", la última parte del libro de Meruane, que corresponde al fluir de conciencia de una enfermera, afianza el registro del despojamiento y lo encarna, justamente, en una imagen singular. Hay una mujer en la banqueta de un parque, bajo la nieve. Parece una estatua que pestañea. La escena tiene una visualidad impactante: es una mendiga, probablemente la Menor, la enferma inicial de Fruta podrida, acechando el hospital en donde convalecen o aguardan las víctimas de la lucha contra la enfermedad. Se trata de los enfermos, en primer lugar, y probablemente de niños procreados por la Mayor u otros vientres de alquiler. Las múltiples conexiones de la novela desembocan en esta circunstancia. Es una escena intensamente teatral, envuelta en un efecto de sordina ligado a la nevada, que trama el monólogo de la enfermera que incluye su diálogo indirecto con la Menor, convertida en mendiga. Pero la identidad que une a la Menor con esa mendiga es fluctuante, la mujer se cubre con papeles, tendría una pierna quebrada, difícilmente podría ser la misma que se fracturó la pierna en la tercer parte de la novela, "Fruta de exportación", porque ha transcurrido cuanto menos una década. En esta escena de potencialidades y condensación extrema convergen referentes que se desplegaron en las páginas previas: aparecen, por ejemplo, una serie de objetos, una manzana marcando la continuación con la primera parte, tal vez envenenada, la manzana de la discordia, la manzana prohibida por el sistema de salud, que, sin embargo, no puede ser la misma. En el final, la enfermera hurga el yeso que cubre la pierna de la mujer y que, según se revela entonces, no cubre nada. Es una galera sin fondo de donde extrae, entre otros, una podadora "extraviada", objetos que condensan el relato y establecen lazos como una suerte de sonda que liga los circuitos fluidos que la novela proyectó. Esa bota de yeso es un objeto enigmático, algo que alude a un cuerpo que ya no es, y que podría contener el universo entero de toda la novela. Se trata de una imagen epifánica, qué duda 
cabe, una imagen que reverbera alguna dimensión de lo inefable.

Regreso entonces a la pregunta inicial de qué puede significar para estas narrativas la inscripción de invenciones circunstanciales, de inventivas en que lector y escritura se encuentren, construyan sentidos gracias a una unidad narrativa eficaz, una imagen de detención, una construcción discursiva de densidad semántica y simbólica que ampare las redes múltiples de los argumentos. Estas inventivas suministran una capa de sentido asegurada, transmisible, casi autónoma, que como las invenciones circunstanciales borgeanas se potencia en una imagen colectiva transmisible a los lectores. En el ensayo En tiempos de catástrofes: Cómo resistir a la barbarie que viene Stengers apela a "repoblar el desierto devastado de nuestras imaginaciones" (130). Lo que Stengers advierte es que la devastación se establece en relación a la im/posibilidad de imaginar otras opciones para el presente, opciones que en el plano literario suponen activar imaginaciones, nutrir una usina de imágenes que discrepe de las fake news. En La modernidad desbordada, Arjun Appadurai pondera la imaginación como hecho social y colectivo, a diferencia de la fantasía, que sería individual y, muy particularmente, que no estaría ligada a una proyectiva.

Regreso a Un año sin primavera. Cohen indica:

\begin{abstract}
No extraña que los neurólogos no acuerden en una teoría universal de cómo codifica el cerebro la información de lo que uno percibe o experimenta el cuerpo. Por eso tampoco se ponen muy acuerdo en cómo nos entendemos. Por lo que nos consta a los legos en la materia, la vía expeditiva es el universo comunicacional; el manejo de los signos. La vía difícil sería el arte. Desde la perspectiva de los neurólogos, un poema es una forma de manifestación de la variabilidad cerebral. Escribirlo, leerlo, escuchar si quiere Meschonnic, una rítmica de la plasticidad (114).
\end{abstract}

Esta respuesta por la vía del arte a una degradación general de los múltiples matices de lo viviente reaparece en muchos pensadores contemporáneos, cuanto menos en quienes comparten cierta alarma por el estado político y la vitalidad de vidas presentes y futuras. Es el caso de Franco Berardi cuando pronostica, consternado, la progresiva degradación y anquilosamiento de los cerebros humanos estancados en subjetividades 
agónicas y carentes de empatía, enfermos por la incapacidad de sincronizar con las tecnologías virtuales. También Berardi pondera este llamado a nuevas plasticidades cerebrales. ¿Con quién se puede sincronizar ética y afectivamente, de qué modo?, parece ser la pregunta. Cristian Geisse, en Catechi, lo pronuncia de otro modo:

Yo morí junto con su cuerpo. Sé que somos indestructibles que, en el fondo, su partida es sólo una ilusión. De todas formas, lo voy a extrañar tanto, como un pedazo de mí que salió a fugarse por el campo. Disfruté todo el proceso y viví nuestra aventura con pasión. Estuve en su mente y en su espíritu el último tramo del trayecto... Yo soy el Catechi. El Catechi soy yo (132-133).

Resulta, sí, esperanzador que esta rítmica de la plasticidad o concreción imaginativa esté en busca de nuevos lugares comunes. El gran lugar común de nuestra época son las redes, pero en ese lugar común se concreta, hay que decirlo, las capas menos personales de los individuos, sometidas a corrientes de afectos inabordables y de difícil discernimiento. Sin embargo, se trata, cualquier escritor lo sabe, de la mayor fuente imaginativa contemporánea. El desafío es cómo darle prestancia y reasignarle sentido a ese movimiento. Muchas narraciones que exploran inventivas narrativas lo hacen con postulaciones de vidas extremas, a contracorriente. Enumeraré algunas: la elección por la enfermedad en Fruta podrida y en Sangre en el ojo de Lina Meruane; la vida como iguana en El animal sobre la piedra de Daniela Tarazona; permanecer en lo inundado en Gongue de Marcelo Cohen; destinarse al silencio en Inclúyanme afuera de María Sonia Cristoff; ser uno mismo y ser perro en Catechi de Cristian Geisse. Cada una de estas ficciones postula esfuerzos imaginativos. Vidas potenciales, entonces, o virtuales, posibles, muchas veces presentadas narrativamente como escenas, sin la ambición de una tipología y recabando fuerzas de su precariedad. Las inventivas narrativas de estas escrituras recientes están muy lejos de las metáforas o imágenes eficientes, evocativas, que suscribe Borges, ni siquiera son plenamente epifánicas. Nacen atrofiadas en la medida en que se someten a abarcar bajo sus postulaciones el espectro casi innumerable de amenazas, y, de ese se trata, yerguen frente a estas amenazas formas resistentes y extremas de vida, modos posibles cuyos 
contornos y respiraciones se esbozan sin precisión, como sombras de lo que será del otro lado, en un espacio y un tiempo hasta el momento inaccesible. $\mathrm{Ni}$ monocordes ni sometidas al realismo, amasan el potencial lingüístico e imaginativo de un escape hacia adelante.

\section{REFERENCIAS}

Appadurai, Arjun. La modernidad desbordada: dimensiones culturales de la globalización. México: FCE, 2001. Impreso.

Berardi, Franco Bifo. Fenomenología del fin. Sensibilidad y mutación colectiva. Buenos Aires: Caja negra, 2017. Impreso.

Borges, Jorge Luis. "La postulación de la realidad". Obras completas. Buenos Aires: Emecé, 1974. 217-221. Impreso.

Cohen, Marcelo. Gongue. Buenos Aires: Interzona, 2012. Impreso.

-. Un año sin primavera (apuntes sobre la poesía y el tiempo que hace). Buenos Aires: Entropía, 2017. Impreso.

Geisse, Cristian. Catechi. Santiago de Chile: Montacerdos, 2018. Impreso.

Hernandez, Felisberto. "La casa inundada". Obras completas 3. Montevideo: Arca Calicanto, 1983. 68-89. Impreso.

Kamenszain, Tamara. Una intimidad inofensiva. Los que escriben con lo que hay. Buenos Aires: Eterna Cadencia, 2016. Impreso.

Latour, Bruno. Enquete sur les modes d'existence. Une antropologie des Modernes. Paris: La Découverte, 2012. Impreso.

Meruane, Lina. Fruta podrida. Buenos Aires: Eterna Cadencia, 2015. Impreso.

Rosset, Clément. Lo real: Tratado de la idiotez. Valencia: Pre-textos, 2004. Impreso.

Saer, Juan José. "La selva espesa de lo real". El concepto de ficción, "Buenos Aires: Ariel", 1997, pp. 267-271.Impreso.

Schweblin, Samanta. Distancia de rescate. Buenos Aires: Random House, 2014. Impreso.

Stengers, Isabelle. En tiempos de catástrofes. Cómo resistir a la barbarie que viene. España: Ned Ediciones, 2017. Impreso. 